\title{
Silica-based composite and mixed-oxide nanoparticles from atmospheric pressure flame synthesis
}

\author{
Kranthi K. Akurati ${ }^{1}$, Rainer Dittmann ${ }^{1}$, Andri Vital ${ }^{1, *}$, Ulrich Klotz ${ }^{1}$, Paul Hug ${ }^{1}$, Thomas Graule ${ }^{1}$ and \\ Markus Winterer ${ }^{2}$ \\ ${ }^{1}$ Laboratory for High Performance Ceramics, Swiss Federal Laboratories for Materials Testing and Research \\ (EMPA), CH-8600, Duebendorf, Switzerland; ${ }^{2}$ Nanoparticle Process Technology, Institute of Combustion \\ and Gas Dynamics, University of Duisburg-Essen, Lotharstr. 1, D-47057, Duisburg, Germany; *Author for \\ correspondence (Tel.: +41-44-823-43-66; E-mail: andri.vital@empa.ch)
}

Received 15 September 2004; accepted in revised form 21 July 2005

Key words: flame aerosol process, atmospheric pressure, mixed oxide, composite, $\mathrm{SiO}_{2}, \mathrm{SnO}_{2}, \mathrm{TiO}_{2}$

\begin{abstract}
Binary $\mathrm{TiO}_{2} / \mathrm{SiO}_{2}$ and $\mathrm{SnO}_{2} / \mathrm{SiO}_{2}$ nanoparticles have been synthesized by feeding evaporated precursor mixtures into an atmospheric pressure diffusion flame. Particles with controlled Si:Ti and Si:Sn ratios were produced at various flow rates of oxygen and the resulting powders were characterized by BET (BrunauerEmmett-Teller) surface area analysis, XRD, TEM and Raman spectroscopy. In the $\mathrm{Si}-\mathrm{O}-\mathrm{Ti}$ system, mixed oxide composite particles exhibiting anatase segregation formed when the Si:Ti ratio exceeded 9.8:1, while at lower concentrations only mixed oxide single phase particles were found. Arrangement of the species and phases within the particles correspond to an intermediate equilibrium state at elevated temperature. This can be explained by rapid quenching of the particles in the flame and is in accordance with liquid phase solubility data of $\mathrm{Ti}$ in $\mathrm{SiO}_{2}$. In contrast, only composite particles formed in the $\mathrm{Sn}-\mathrm{O}-\mathrm{Si}$ system, with $\mathrm{SnO}_{2}$ nanoparticles predominantly found adhering to the surface of $\mathrm{SiO}_{2}$ substrate nanoparticles. Differences in the arrangement of phases and constituents within the particles were observed at constant precursor mixture concentration and the size of the resultant segregated phase was influenced by varying the flow rate of the oxidant. The above effect is due to the variation of the residence time and quenching rate experienced by the binary oxide nanoparticles when varying the oxygen flow rate and shows the flexibility of diffusion flame aerosol reactors.
\end{abstract}

\section{Introduction}

Nanoparticles have attracted the attention of an increasing number of researchers from several disciplines in the last decade. Their extremely small size is responsible for the different properties (electronic, optical, electrical, magnetic, chemical and mechanical) compared to their bulk and micrometer-scale counterparts, and makes them suitable for novel applications. Various kinds of pure oxide nanoparticles are already being produced on an industrial scale and silica $\left(\mathrm{SiO}_{2}\right)$ is one of the major products (Wegner \& Pratsinis, 2003a). Silica-based nanocomposites and multicomponent nanoparticles have generated much interest as they have the potential for improved 
performance when compared to the single-component nanoparticles.

The combination of $\mathrm{SiO}_{2}$ with titania $\left(\mathrm{TiO}_{2}\right)$ represents a novel class of material that has attracted much attention in recent years and has been extensively investigated for a wide range of applications: catalysts (Stark et al., 2001) and supports for a wide variety of chemical reactions that possess enhanced thermal and mechanical stability due to $\mathrm{SiO}_{2}$ while preserving the catalytic performance of $\mathrm{TiO}_{2}$ (Srinivasan et al., 1994; Dagan et al., 1995), protective coatings on stainless steel against oxidation and chemical attack (Atik \& Zarzycki, 1994), antireflective coatings for optical glasses (Yu-Zhang et al., 1994), glass materials with low thermal expansion coefficients (Zhu \& Kosugi, 1996) and high refraction indices (Song et al., 1998) and fillers in polymer composites for photonic crystals (Miyamoto et al., 2004). Depending on the desired application of the final product, the $\mathrm{Si}-\mathrm{O}-\mathrm{Ti}$ system offers the opportunity to control the arrangement of the components, that means to form either $\mathrm{TiO}_{2} / \mathrm{SiO}_{2}$ composites or mixed oxide $\mathrm{Si}-\mathrm{O}-\mathrm{Ti}$ phases. In other words, there arises a unique opportunity to derive structures and compositions with individually tailored physico-chemical reactivity and properties. For example, for low thermal expansion glasses containing less than $12 \mathrm{wt} \% \mathrm{TiO}_{2}$ in $\mathrm{SiO}_{2}$, complete mixing (i.e., the formation of $\mathrm{Si}-\mathrm{O}-\mathrm{Ti}$ linkages) is desired (Schultz, 1976). However, in optical wave guide applications, phase-segregated regions enriched in $\mathrm{TiO}_{2}$ improve the fatigue resistance of the optical fiber by preventing the propagation of cracks (Backer et al., 1991).

Tin dioxide $\left(\mathrm{SnO}_{2}\right.$, stannic oxide, cassiterite) is a semiconducting material of considerable technological importance with many applications such as solar cells (Niles et al., 1993), gas sensors (Cox et al., 1998; Kennedy et al., 2000) and conductive substrates (Ishida et al., 1993). Owing to the large surface of $\mathrm{SnO}_{2}$ nanoparticles, they have the tendency to aggregate and reveal a weak thermal stability, which strongly affects their application. Binary oxides of $\mathrm{SnO}_{2} / \mathrm{SiO}_{2}$ have been shown to overcome this disadvantage (Feng et al., 2003). Materials combining $\mathrm{SiO}_{2}$ with tin dioxide shows improved sensor performance (Popova et al., 2004) and bases for immobilization of electroactive species for use as electrochemical sensors (Carturan et al., 1995). Addition of tin oxide to
$\mathrm{SiO}_{2}$ increases the surface area of resulting composite oxides and enhances the catalytic activity for dehydration reactions (Salas et al., 1997). Special interest in studying the $\mathrm{SnO}_{2} / \mathrm{SiO}_{2}$ system arises from the high UV photosensitivity of the material (Canevali et al., 2001) which allows the realization of several optical devices, mainly based on the principle of fiber Bragg gratings (Brambilla et al., 2000; Chiodini et al., 2001, 2002).

Common methods applied to prepare $\mathrm{TiO}_{2} /$ $\mathrm{SiO}_{2}$ mixed oxides and composites are sol-gel hydrolysis (Anderson \& Bard, 1995), co-precipitation (Stakheev et al., 1993) and flame hydrolysis (Hung \& Katz, 1992). Of these, sol-gel hydrolysis is the most widely used method. In sol-gel processes, domain formation due to the differences in the hydrolysis and the condensation rates of Ti- and Si-alkoxides was identified to be a major problem in the preparation of mixed oxides (Aizawa et al., 1991). Though the two-stage hydrolysis, which is performed under acidic conditions seems to have overcome this problem and results in the best $\mathrm{Si}-\mathrm{O}-\mathrm{Ti}$ connectivity and the highest homogeneity (Miller et al., 1994), the low crystallinity of the product powder and impurities associated with the wet-chemical process still remain an open issue.

Powder synthesis in the gas phase is carried out either by reaction of precursor gases (gas-toparticle conversion), or by evaporation and/or reaction of suspended precursor particles or droplets (particle-to-particle conversion) in a gas stream (Pratsinis \& Vemury, 1996). Gas-to-particle conversion routes, such as atmospheric pressure flame aerosol processes, permit particles to be built from molecules all the way up to the desired size and allow to create complex chemical structures combined with good crystallinity, which is useful in producing multicomponent materials at relatively low cost compared to vacuum synthesis routes and enable continuous production, while wet chemical or milling processes are often performed in a batch form (Kodas et al., 1989).

Hung and Katz (1992) studied the formation of $\mathrm{SiO}_{2} / \mathrm{TiO}_{2}$ particles in a counter flow diffusion flame burner with in-situ characterization of the particle size. The effects of temperature and the Si:Ti concentration ratios on particle morphology were investigated. Depending on the precursor concentration, titania particles with varying 
surface concentrations of silica particles could be prepared: discrete silica particles were observed at low Si:Ti ratios, while a thick layer of silica formed at high Si:Ti ratios. Vemury and Pratsinis (1995) investigated the effect of $\mathrm{SiO}_{2}$ dopant on the phase transformation and particle size of $\mathrm{TiO}_{2}$ and reported that addition of $\mathrm{SiO}_{2}$ inhibits the formation of rutile and decreases the primary particle size. Ehrmann et al. (1998) synthesized $\mathrm{TiO}_{2} / \mathrm{SiO}_{2}$ particles in a premixed flat flame using three different precursor sources for silica $\left(\mathrm{SiBr}_{4}, \mathrm{SiCl}_{4}\right.$, HMDSO) and $\mathrm{TiCl}_{4}$ as the titania precursor. They showed that nucleation of silica particles, occurring either prior to or after titania, is affected by the precursor source. They also systematically investigated the dependence of precursor volume loading and particle size (prevailing before the reaction of the second species) on the morphology of the resultant binary oxide nanoparticles, where either a scavenging of one component on the other or formation of two chemically-distinct phases was observed. In a subsequent study, Ehrmann et al. (1999) synthesized $\mathrm{TiO}_{2} / \mathrm{SiO}_{2}$ nanoparticles in a similar reactor at various $\mathrm{Si}$ :Ti ratios. Phase segregation in qualitative agreement with the binary phase diagram and thermodynamic considerations was observed to varying degrees as a function of the Si:Ti ratio. Stark et al. (2001) prepared $\mathrm{SiO}_{2} /$ $\mathrm{TiO}_{2}$ nanoparticles in a single diffusion flame, where $\mathrm{TiO}_{2}$ formed as discrete particles on $\mathrm{SiO}_{2}$ and mixed oxide ( $\mathrm{Ti}$ substitution in the lattice of $\mathrm{SiO}_{2}$ ) formation is not reported. Apart from the flame reactors, synthesis of coated and core-shell particles of $\mathrm{SiO}_{2} / \mathrm{TiO}_{2}$ has also been studied in hot wall reactors (Powell et al., 1997; Lee et al., 2002).

The synthesis of $\mathrm{SnO}_{2} / \mathrm{SiO}_{2}$ nanoparticles using the flame aerosol method has not been acquainted yet. Salas et al. (1997), Chiodini et al. (2001) and Cardoso et al. (2004) reported on the synthesis of $\mathrm{SnO}_{2} / \mathrm{SiO}_{2}$ binary oxides via sol-gel processes. In all the above references, the product powders had a very high specific surface area and consisted of segregated $\mathrm{SnO}_{2} / \mathrm{SiO}_{2}$ nanoparticles. Mixed $\mathrm{Si}-\mathrm{O}-\mathrm{Sn}$ phases were only observed with $\mathrm{SnO}_{2}$ concentrations up to $1 \mathrm{wt} \%$.

In the present study, single-step formation of $\mathrm{TiO}_{2} / \mathrm{SiO}_{2}$ and $\mathrm{SnO}_{2} / \mathrm{SiO}_{2}$ composite and mixedoxide nanoparticles has been investigated in an atmospheric pressure diffusion flame. Silica was chosen as main component because of its inertness. Titania as a dopant was investigated due to its photocatalytic properties and tin oxide was chosen for its gas sensing properties. With $\mathrm{TiO}_{2} / \mathrm{SiO}_{2}$, by varying the concentration of $\mathrm{Si}: \mathrm{Ti}$, formation of mixed oxides (at low concentrations of $\mathrm{TiO}_{2}$ ) and chemically distinct phases are observed. On the other hand, by varying the concentration of $\mathrm{Si}: \mathrm{Sn}$, size of the $\mathrm{SnO}_{2}$ particles condensed on $\mathrm{SiO}_{2}$ particles is controlled. Furthermore, at a given concentration of $\mathrm{Si}: \mathrm{Sn}$, particle size is controlled by varying the flow rate of the oxidant. Homogeneous distribution of ultrafine, non-aggregated $\mathrm{SnO}_{2}$ particles on $\mathrm{SiO}_{2}$ substrate particles is achieved which is not reported till now.

\section{Experimental}

\section{Apparatus}

Figure 1 shows the experimental set-up with the aerosol flame reactor, the reactant dosing and delivery system and the particle collection unit. A co-flow diffusion burner consisting of three concentric tubes was used. The central tube is $4.8 \mathrm{~mm}$ in diameter and the spacing from the centre to the middle tube and the middle to the outer tube is $0.3 \mathrm{~mm}$ and $0.85 \mathrm{~mm}$, respectively.

Methane $\left(\mathrm{CH}_{4}\right.$, purity $>99.95 \%$, Carbagas, Switzerland) was employed as fuel, and oxygen $\left(\mathrm{O}_{2}\right.$, purity $>99.95 \%$, Carbagas, Switzerland $)$ as oxidant. Titanium-tetraisopropoxide (TTIP, Ti $\left(\mathrm{C}_{3} \mathrm{H}_{7} \mathrm{O}\right)_{4}$, purity $>99 \%$, VWR International, Switzerland), Tetramethyltin (TMT, $\mathrm{Sn}\left(\mathrm{CH}_{3}\right)_{4}$, purity $>99 \%$, Fluka, Switzerland) and hexamethyldisiloxane (HMDSO, $\mathrm{O}\left(\mathrm{SiC}_{3} \mathrm{H}_{9}\right)_{2}$, purity $>99 \%$, VWR International, Switzerland) were used as precursors for $\mathrm{TiO}_{2}, \mathrm{SnO}_{2}$ and $\mathrm{SiO}_{2}$, respectively. Controlled amounts of precursors were fed to the evaporator (Hovacal, IAS, Germany) through independent mass flow controllers (Bronkhorst HI-TEC, Netherlands) and $86 \mathrm{l} / \mathrm{h}$ of nitrogen $\left(\mathrm{N}_{2}\right.$, purity $>99.995 \%$, Carbagas, Switzerland) was used as carrier gas to transport the vaporized precursor mixture to the central tube of the burner. The flow rates of the single precursors were varied to produce defined precursor concentrations in the flame as given in Table 1, while the total precursor flow was always $23 \mathrm{~g} / \mathrm{h}$ in each experiment. Oxygen was fed through the outer annulus, nitrogen $(33 \mathrm{l} / \mathrm{h})$ as a lift gas (to lift the flame from the burner face) through the inner 


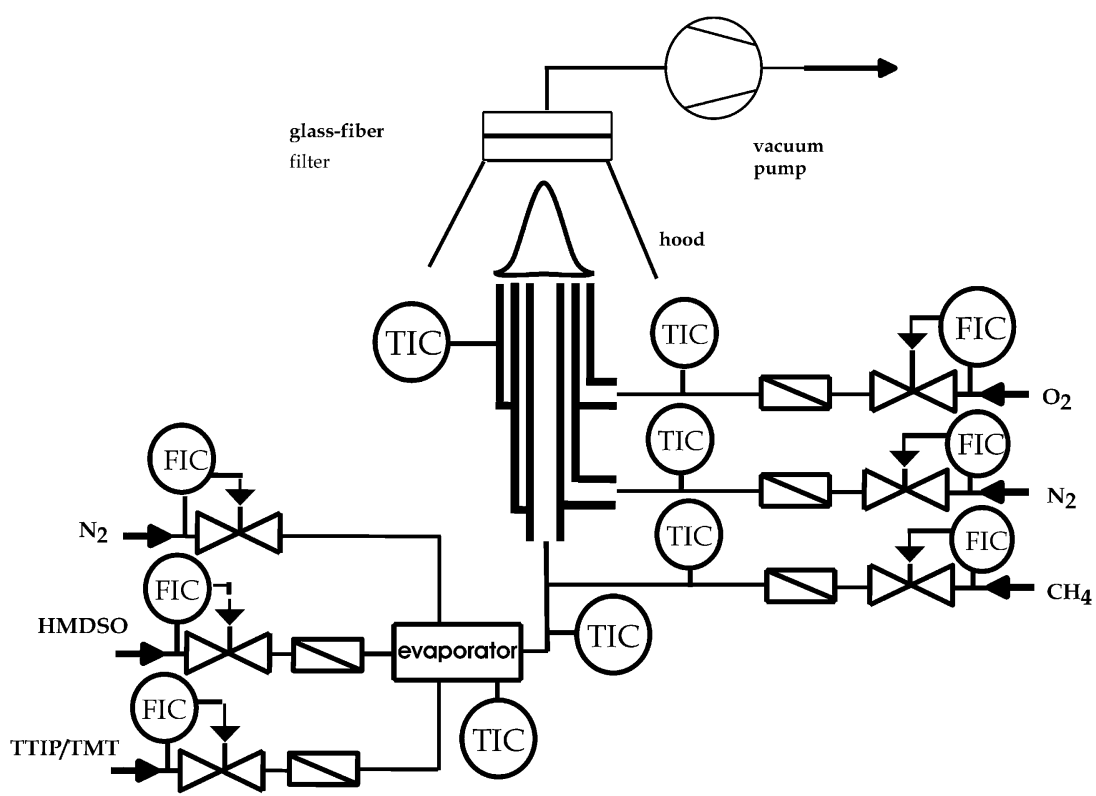

Figure 1. Experimental set-up for the synthesis of $\mathrm{TiO}_{2} / \mathrm{SiO}_{2}$ and $\mathrm{SnO}_{2} / \mathrm{SiO}_{2}$ nano-powders by atmospheric pressure flame aerosol process.

annulus and methane $(44 \mathrm{l} / \mathrm{h})$ through the center tube, resulting in a single diffusion flame. Experiments were performed with oxygen flow rates of 150-1340 1/h while keeping nitrogen and methane flow rates constant. All gas flow rates were controlled by mass flow controllers (Bronkhorst HI-TEC, Netherlands). The evaporator, the gas delivery tubes to the burner and the burner itself were kept at $175^{\circ} \mathrm{C}$ for TTIP/HMDSO and at $120^{\circ} \mathrm{C}$ for TMT/HMDSO, respectively, to prevent condensation of precursor vapors. The product particles were collected on borosilicate glass fiber filters (Type GF50, Schleicher and Schuell, Germany) placed inside an open-faced, stainless steel filter holder connected to a vacuum pump (Trivac A - D16A, Leybold, Switzerland). The filter (150 mm diameter) was fixed $55 \mathrm{~cm}$ vertically above the tip of the burner in all experiments.

\section{Characterization}

The specific surface area (SSA) of the product powder was determined from a five-point $\mathrm{N}_{2}$ adsorption isotherm obtained from BET (Brunauer-Emmett-Teller) measurements using a Beckman-Coulter SA3100 (Beckman-Coulter, Switzerland). Prior to BET analysis, the powder samples were degassed at $200^{\circ} \mathrm{C}$ for 180 min under flowing $\mathrm{N}_{2}$ atmosphere to remove adsorbed $\mathrm{H}_{2} \mathrm{O}$ from the surface. Assuming monodisperse, spherical primary particles, the BET-equivalent particle diameter $\left(d_{\mathrm{BET}}\right)$ was calculated by $d_{\mathrm{BET}}=$ $6 /(\rho *$ SSA $)$, where $\rho$ is the particle density.

The primary particle size, shape and morphology of the particles was investigated by transmission electron microscopy (TEM). Powder samples were dispersed in isopropanol (purity $>99.5 \%$,

Table 1. Vapor flow rates and resulting mole ratios of precursor species

\begin{tabular}{|c|c|c|c|c|c|c|c|c|c|c|}
\hline Flow rate at $\mathrm{STP}(1 / \mathrm{min})$ & HMDSO & TTIP & TMT & $\begin{array}{l}23.3: 1 \\
\mathrm{Si}: \mathrm{Ti}\end{array}$ & $\begin{array}{l}9.8: 1 \\
\mathrm{Si}: \mathrm{Ti}\end{array}$ & $\begin{array}{l}3.2: 1 \\
\mathrm{Si}: \mathrm{Ti}\end{array}$ & $\begin{array}{l}0.98: 1 \\
\text { Si:Ti }\end{array}$ & $\begin{array}{l}\text { 17.2:1 } \\
\text { Si:Sn }\end{array}$ & $\begin{array}{l}6.1: 1 \\
\text { Si:Sn }\end{array}$ & $\begin{array}{l}1.8: 1 \\
\text { Si:Sn }\end{array}$ \\
\hline HMDSO & 0.0528 & & & 0.0459 & 0.0390 & 0.0252 & 0.0114 & 0.0469 & 0.0388 & 0.0241 \\
\hline TTIP & & 0.0302 & & 0.0039 & 0.0078 & 0.0157 & 0.0236 & & & \\
\hline TMT & & & 0.0480 & & & & & 0.0054 & 0.0127 & 0.0260 \\
\hline
\end{tabular}


Fluka, Switzerland) and a few drops of the dispersion were dried on carbon-coated copper grids (Plano GmbH, Germany). The TEM analysis was performed on a Philips CM30 electron microscope operating at $200 \mathrm{kV}$.

X-ray diffraction (XRD) was used for identification of the crystal phases. Diffraction measurements were performed with a Siemens D500 instrument using Ni-filtered $\mathrm{Cu}-\mathrm{K} \alpha$ of wavelength $1.5418 \AA$. A $2 \theta$ scan range from 10 to $80^{\circ}$, a scanning step size of $0.025^{\circ}$ and a scintillation counter detector were used. Curve fitting and integration was carried out using proprietary software from Siemens (DiffracAT. V3.2).

Raman spectra were obtained in backscattering geometry using a Renishaw Ramascope 2000 (Renishaw plc, Gloucestershire, UK) with a spectral resolution of $1 \mathrm{~cm}^{-1}$. The $633 \mathrm{~nm}$ line of the HeNe-laser was focused on the samples through $50 \times$ objective of the microscope, the laser beam power on the sample being $0.5 \mathrm{~mW}$. The samples were investigated at room temperature.

Chemical analysis of the product powders was performed on a Philips (PW 2400) wavelengthdispersive X-ray fluorescence spectrometer
(WD-XRF). This instrument is a sequential spectrometer with an end-window $\mathrm{Rh} \mathrm{X}$-ray tube and $3000 \mathrm{~W}$ maximum power. The software UniQuant Version 5.44 (Omega Data Systems) was used for calculation of the element concentration.

\section{Results and discussion}

Pure oxides - BET, XRD and TEM

Figures 2 and 3 show the specific surface area and BET-equivalent particle size $\left(d_{\mathrm{BET}}\right)$ of the pure oxide species as a function of oxygen flow rate. Irrespective of the material, increasing the oxygen flow rate increases the specific surface area and decreases $d_{\mathrm{BET}}$. Increasing the oxygen flow rate reduces the flame temperature (Zhu \& Kosugi, 1996) as additional $\mathrm{O}_{2}$ flow dissipates the generated heat very quickly and shortens the flame length (Mueller et al., 2004) as the combustion rate is enhanced. Consequently, particle residence time at high temperatures is reduced, thereby producing the particles with high specific surface area and low $d_{\mathrm{BET}}$. As the materials with different

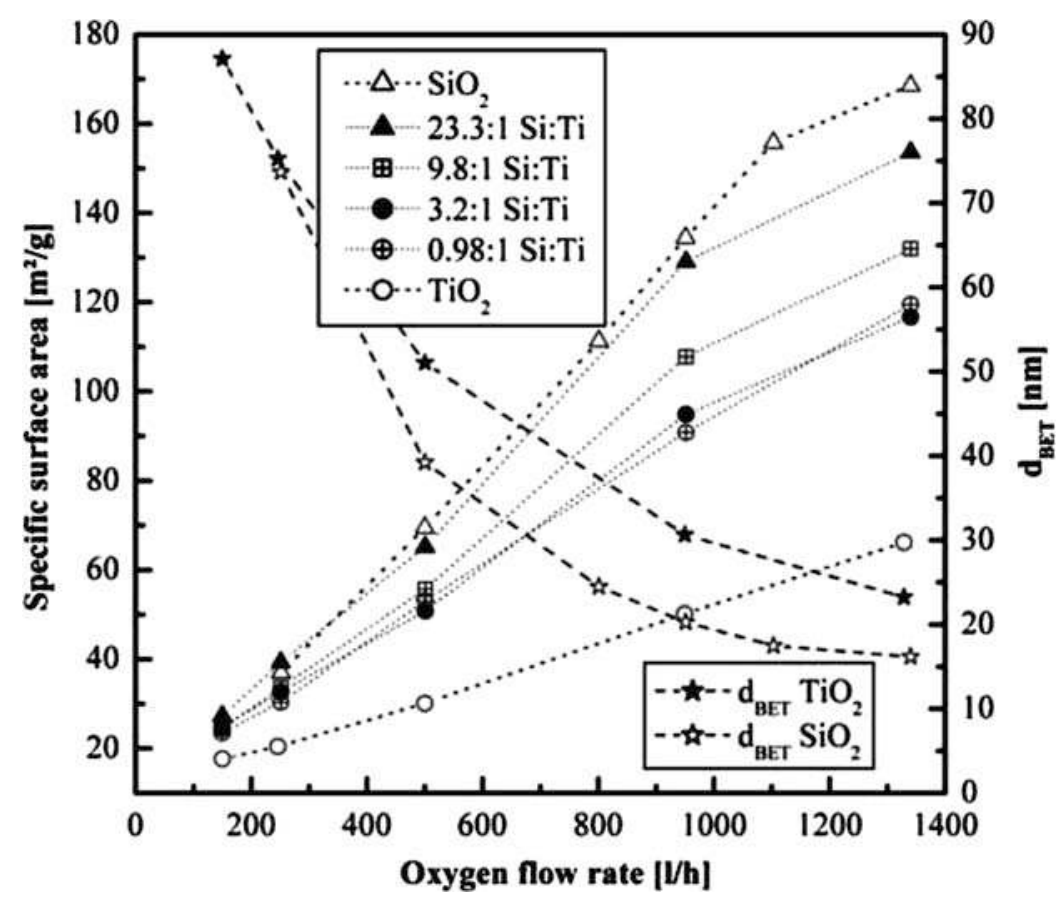

Figure 2. Specific surface area of pure $\mathrm{TiO}_{2}, \mathrm{SiO}_{2}$ and mixed $\mathrm{TiO}_{2} / \mathrm{SiO}_{2}$ powders synthesized as a function of oxygen flow rate and Si:Ti ratio at $44 \mathrm{l} / \mathrm{h} \mathrm{CH}_{4}, 86 \mathrm{l} / \mathrm{h} \mathrm{N} \mathrm{N}_{2}$ and a constant total precursor mass flow (HMDSO plus TTIP) of $23 \mathrm{~g} / \mathrm{h}$. 


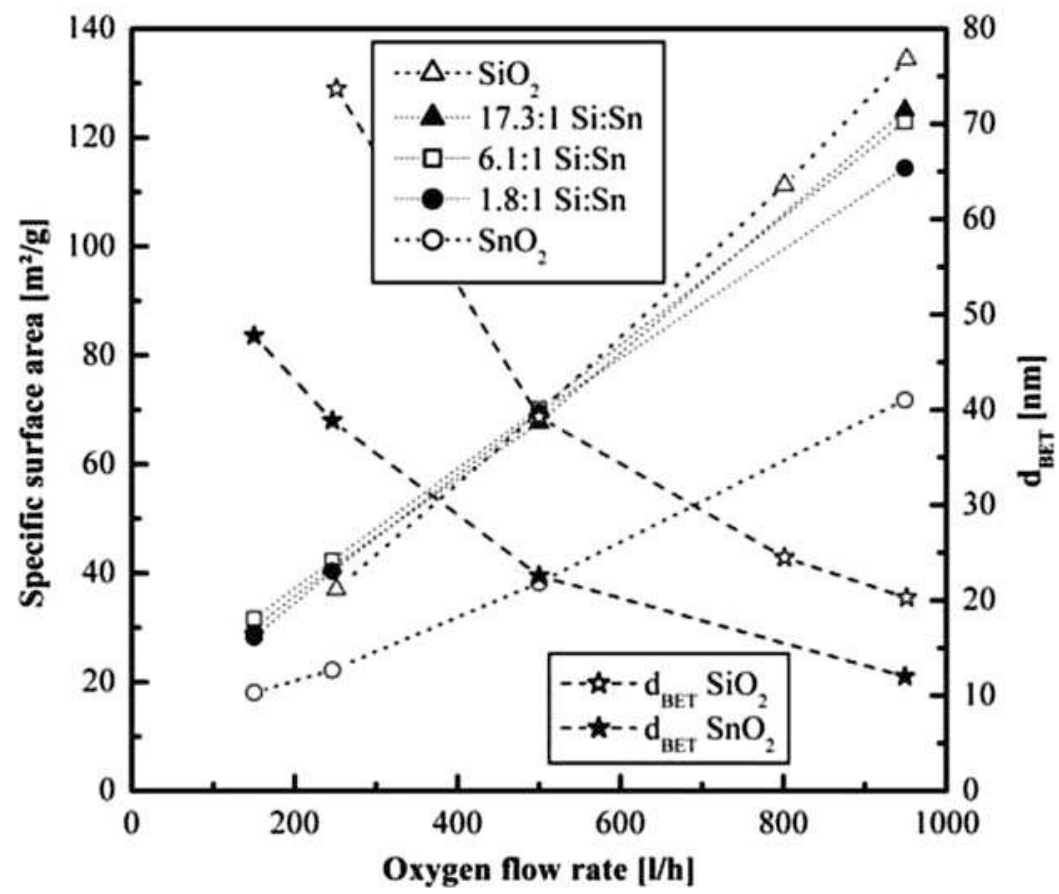

Figure 3. Specific surface area of pure $\mathrm{SnO}_{2}, \mathrm{SiO}_{2}$ and composite $\mathrm{SnO}_{2} / \mathrm{SiO}_{2}$ powders synthesized as a function of oxygen flow rate at $44 \mathrm{l} / \mathrm{h} \mathrm{CH} 4,86 \mathrm{l} / \mathrm{h} \mathrm{N} \mathrm{N}_{2}$ and a constant total precursor mass flow (HMDSO plus TMT) of $23 \mathrm{~g} / \mathrm{h}$.

densities are synthesized in the present study, it is reasonable to compare them basing on the BET equivalent particle size $d_{\mathrm{BET}}$ in preference to the specific surface area. The differences in the $d_{\mathrm{BET}}$ between these oxides synthesized under similar conditions stem from their different sintering rates and material properties.

The decrease of the $d_{\mathrm{BET}}$ with increasing oxygen flow rate is greater for $\mathrm{TiO}_{2}$ and $\mathrm{SiO}_{2}$ when compared to $\mathrm{SnO}_{2}$. $\mathrm{TiO}_{2}$ sinters by grain boundary diffusion (Astier \& Vergnon, 1976), which is moderately sensitive to flame temperature (Vemury et al., 1997) and hence sintering rate is much faster than $\mathrm{SiO}_{2}$ (Hung \& Katz, 1992). Due to this, particles coalesce much faster, leading to the large, spherical (Figure 4a) and single $\mathrm{TiO}_{2}$ particles with less specific surface area (large BET equivalent particle size) when compared to $\mathrm{SiO}_{2}$.
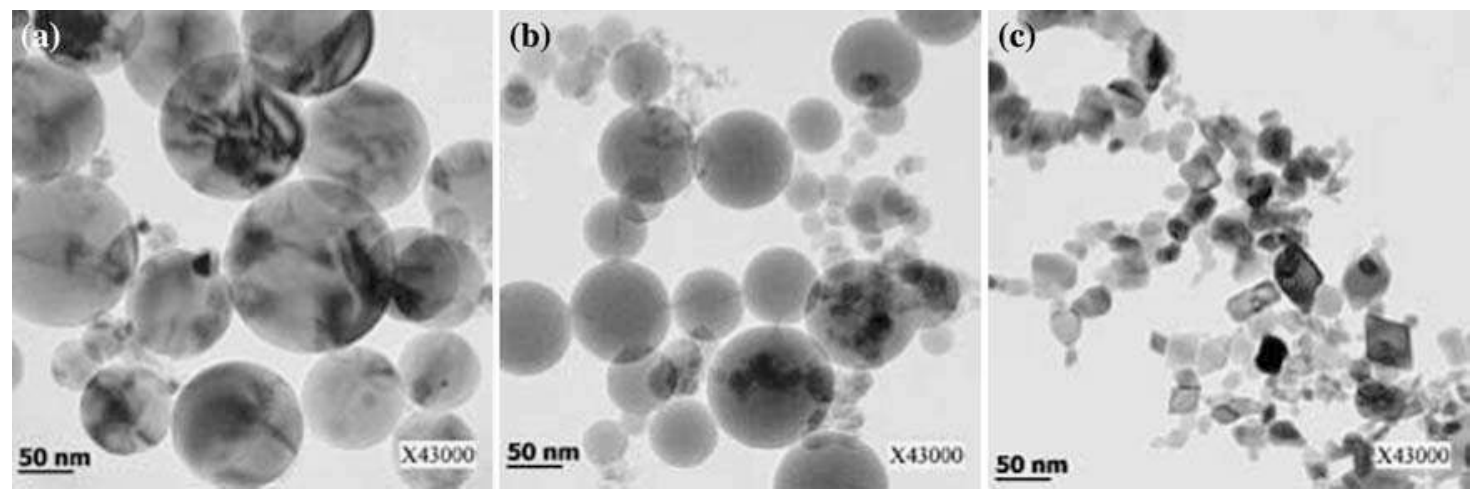

Figure 4. TEM images of pure oxide particles synthesized at flow rates of $250 \mathrm{l} / \mathrm{h} \mathrm{O}_{2}, 44 \mathrm{l} / \mathrm{h} \mathrm{CH}_{4}, 86 \mathrm{l} / \mathrm{h} \mathrm{N} \mathrm{N}_{2}$ and $23 \mathrm{~g} / \mathrm{h}$ precursor flow rate: (a) $\mathrm{TiO}_{2}$, (b) $\mathrm{SiO}_{2}$ and (c) $\mathrm{SnO}_{2}$. 
Sintering of silica proceeds by viscous flow (Kingery et al., 1976) and is therefore very sensitive to temperature. A reduction of the flame temperature and residence time with increasing oxygen flow rate hinders complete particle coalescence resulting in aggregates of small primary particles (Zhu \& Pratsinis, 1997) which are responsible for the small $d_{\mathrm{BET}}$ (Confirmed with TEM pictures, not shown). At low oxygen flow rate flame temperature and particle residence time is sufficiently high for complete coalescence to occur, resulting in non-aggregated large primary particles with low specific surface area (Figure 4b).

The particle formation sequence and the sintering mechanism of $\mathrm{SnO}_{2}$ are completely different from $\mathrm{SiO}_{2}$ and $\mathrm{TiO}_{2}$. Tin dioxide has a melting point of $1625^{\circ} \mathrm{C}$ and sinters by evaporation-condensation (Harrison \& Willett, 1989). In the initial hottest part of the flame, TMT precursor oxidizes to $\mathrm{SnO}$ vapor $\left(T_{\mathrm{m}}, \mathrm{SnO}=1080^{\circ} \mathrm{C}\right)$ (Lindackers et al., 1998). When traversing through the flame, which is having a high oxidizing potential as the experiments are conducted at oxygen rich conditions, $\mathrm{SnO}$ vapor oxidizes and condenses to the more stable $\mathrm{SnO}_{2}$ phase (Figure 5). The size of the $\mathrm{SnO}_{2}$ particles depends on the precursor concentration and particle residence time (Vemury et al., 1997). These parameters influence coagulation of
$\mathrm{SnO}$ vapor as well as its oxidation to $\mathrm{SnO}_{2}$ particles, both of which are formed in the early stages of the flame. As the particle formation mechanism is not strongly dependent on temperature, variation in the resulting particle sizes with changing oxygen flow rate is only due to the changes in the precursor concentration, such as the dilution induced by excess oxygen, resulting in the small $d_{\mathrm{BET}}$ values compared to $\mathrm{TiO}_{2}$ and $\mathrm{SiO}_{2}$. Variation of specific surface area follows the similar trend with the variation of oxygen flow rate as reported by Pratsinis and Vemury (1996), Zhu and Kosugi (1996) and Zhu and Pratsinis (1997) for $\mathrm{SnO}_{2}$, $\mathrm{TiO}_{2}$ and $\mathrm{SiO}_{2}$, respectively. But the results cannot be compared quantitatively as the flow rates of the reactants in the present study vary considerably with the above references.

TEM analysis revealed that the silica aerosol synthesized at $250 \mathrm{l} / \mathrm{h} \mathrm{O}_{2}$ flow rate contains very fine aggregates and large spherical single particles (Figure 4b) and X-ray diffraction shows that the $\mathrm{SiO}_{2}$ produced is amorphous for all oxygen flow rates. The $\mathrm{TiO}_{2}$ particles are spherical and nonaggregated, ranging in diameter from 10 to $80 \mathrm{~nm}$ (Figure 4a) and consist of pure anatase. The $\mathrm{SnO}_{2}$ particles have a faceted morphology (Figure 4c) and exhibit the cassiterite phase. The particle size distributions are rather broad for all the

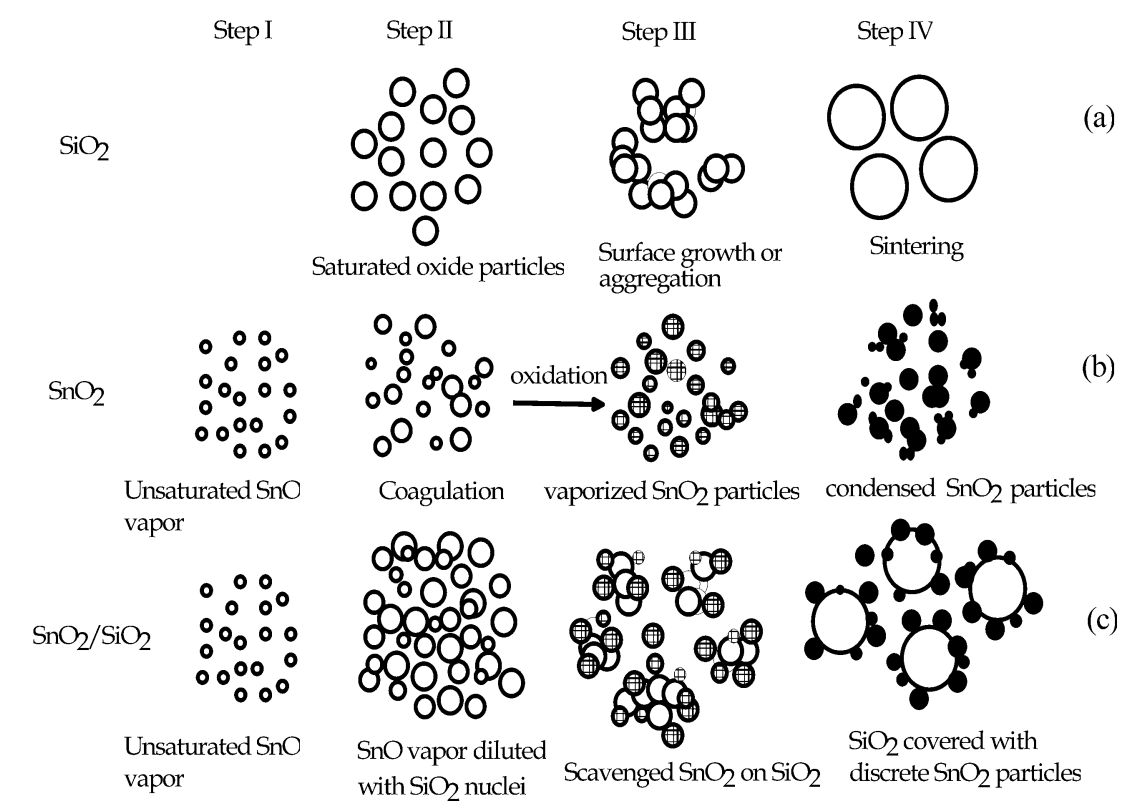

Figure 5. Scheme of the particle growth processes for (a) $\mathrm{SiO}_{2}$, (b) $\mathrm{SnO}_{2}$ and (c) $\mathrm{SnO}_{2} / \mathrm{SiO}_{2}$ mixtures. 

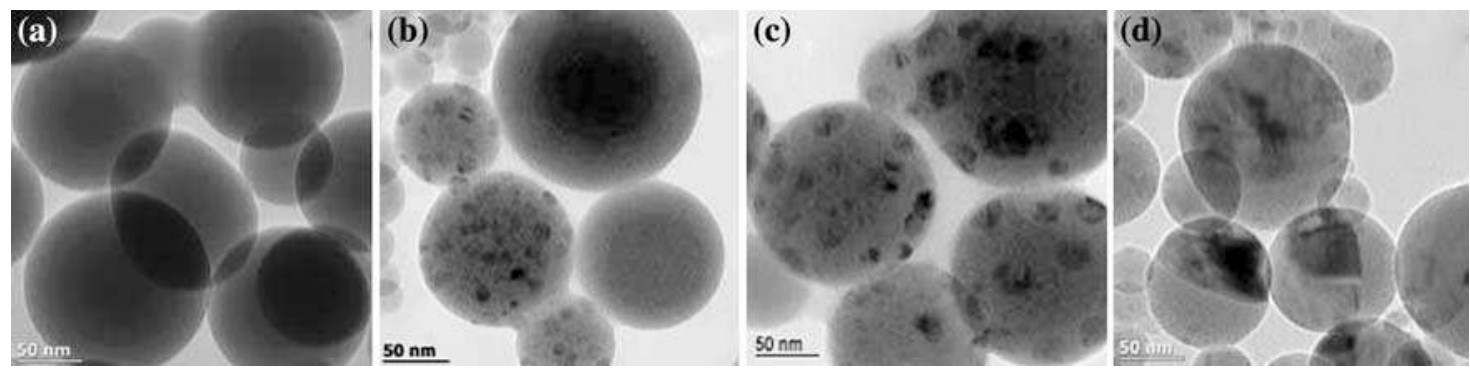

Figure 6. TEM images of mixed $\mathrm{TiO}_{2} / \mathrm{SiO}_{2}$ powders produced at various mole concentrations of $\mathrm{HMDSO} / \mathrm{TTIP}$ precursors and at 44 1/h $\mathrm{CH}_{4}, 86$ 1/h N $\mathrm{h}_{2}$ and 250 1/h O 2 : (a) Si:Ti ratio 23.3:1, (b) Si:Ti ratio 9.8:1, (c) Si:Ti ratio 3.2:1 and (d) Si:Ti ratio 0.98:1.

nanoparticles, a factor attributed to the steep axial and radial temperature gradients which usually exist in diffusion flames (Johannessen et al., 2001).

\section{Binary oxide - BET, TEM, XRD and Raman spectroscopy}

Figure 2 shows the $\mathrm{SSA}$ of the mixed $\mathrm{SiO}_{2} / \mathrm{TiO}_{2}$ particles at various concentrations of $\mathrm{TiO}_{2}$ and as a function of oxygen flow rate. For all concentrations of $\mathrm{TiO}_{2}$, the specific surface area increases with increasing oxygen flow rate. This correlates with the general trend shown above for the pure oxide particles. It is worth noting that the SSA's of the binary oxides lie in between the values of pure $\mathrm{SiO}_{2}$ and $\mathrm{TiO}_{2}$ and at a given oxygen flow rate, and that the SSA decreases with increasing $\mathrm{TiO}_{2}$ concentration.

Representative TEM images of the mixed $\mathrm{SiO}_{2} /$ $\mathrm{TiO}_{2}$ oxides synthesized at $250 \mathrm{l} / \mathrm{h} \mathrm{O}_{2}$ are shown in Figure 6. Complete mixing of titania in the silica is seen for the 23.3:1 Si:Ti sample where no crystalline domains of $\mathrm{TiO}_{2}$ are present (Figure 6a). Minor segregation of $\mathrm{TiO}_{2}$, which is evident from the image contrast arising from the difference in atomic number and crystallinity of $\mathrm{SiO}_{2}$ and $\mathrm{TiO}_{2}$ particles, is observed at 9.8:1 $\mathrm{Si}: \mathrm{Ti}$ (Figure 6b). Nucleated clusters of $\mathrm{TiO}_{2}$ tend to grow by coalescence to form crystalline domains within the $\mathrm{SiO}_{2}$. Several authors (Pratsinis \& Vemury, 1996; Jang \& Kim, 2001) reported the increase of particle size with increasing concentration of precursor flow, which can be attributed to faster particle growth by higher particle concentrations in the flame. Consequently increased segregation of $\mathrm{TiO}_{2}$ becomes apparent with increasing $\mathrm{TiO}_{2}$ content, as can be seen in the 3.2:1 and 0.98:1 Si:Ti samples (Figure 6c, d).
Segregation behavior can be explained in conjunction with the equilibrium phase diagram of the $\mathrm{TiO}_{2} / \mathrm{SiO}_{2}$ system (DeVries et al., 1954). The maximum temperature ${ }^{1}$ in the flames is higher than the melting point of $\mathrm{SiO}_{2}$ and $\mathrm{TiO}_{2}$ and, therefore, it is very likely that particles will be in the liquid state in the initial stages of nucleation and growth. Under these conditions, diffusional processes are rapid and phase compositions will be close to those predicted by the equilibrium diagram (Ehrmann et al., 1999). Particles grow as they traverse through the flame and are quenched from approximately $2000^{\circ} \mathrm{C}$ (Mueller et al., 2004) to ambient temperature when they are collected on the filter at a short distance from the flame. Due to this rapid cooling, diffusion processes are inhibited and high-temperature equilibrium phase composition (mixed oxide) seems to hold, however not the equilibrium phases, rutile and cristobalite, as predicted by the phase diagram. This is confirmed by the presence of anatase and amorphous silica in the XRD patterns (Figure 7).

In the 23.3:1 Si:Ti sample, where complete solubility of $\mathrm{TiO}_{2}$ in $\mathrm{SiO}_{2}$ is expected from the phase diagram, a homogenous single phase mixed oxide liquid is formed at temperatures above $1650^{\circ} \mathrm{C}$. Due to the rapid quenching, this single phase is retained at room temperature without segregation of $\mathrm{TiO}_{2}$ (Figure 6a). For the 9.8:1 Si:Ti sample,

\footnotetext{
1 The flame temperatures for the parameter set applied in this study for pure $\mathrm{SiO}_{2}$ production have been measured by Mueller et al. (2004) using similar flow rate of the fuel and oxidant. The maximum increase of enthalpy of the flame associated with the feeding of TTIP and TMT precursors is only 3 and $11 \%$, respectively. As the variation in the flame enthalpy is less, temperature profiles are assumed to follow the same trend with negligible affect on the resultant particle characteristics of $\mathrm{TiO}_{2} / \mathrm{SiO}_{2}$ and $\mathrm{SnO}_{2} / \mathrm{SiO}_{2}$.
} 


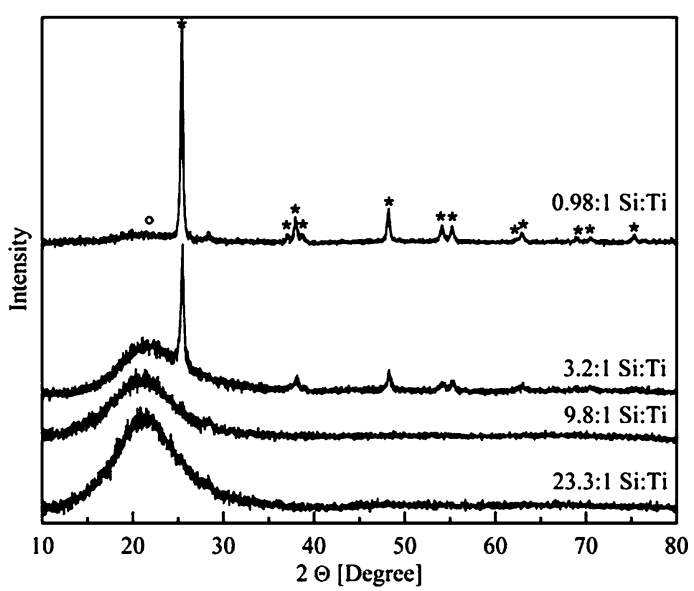

Figure 7. XRD patterns of mixed $\mathrm{TiO}_{2} / \mathrm{SiO}_{2}$ powders produced at various concentrations of HMDSO/TTIP and at $44 \mathrm{l} / \mathrm{h} \mathrm{CH} 4,86 \mathrm{l} / \mathrm{h} \mathrm{N} \mathrm{N}_{2}$ and $250 \mathrm{l} / \mathrm{h} \mathrm{O}_{2}$; ${ }^{\circ}$ indicates amorphous silica, $*$ indicates peaks corresponding to anatase phase of $\mathrm{TiO}_{2}$.

slight anatase segregation was observed along with an amorphous mixed oxide phase. This is in agreement with the phase diagram, which indicates a homogenous single phase liquid at high temperature and the segregation of $\mathrm{TiO}_{2}$ during cooling. As the particles synthesized in diffusion flames usually experience different temperature histories, segregation is not uniform. Two immiscible liquids are in equilibrium at temperatures above $1780^{\circ} \mathrm{C}$ for the $3.2: 1$ and $0.98: 1 \mathrm{Si}: \mathrm{Ti}$ samples. Crystalline domains of anatase within a silica-rich mixed-oxide matrix were found in both samples, and in addition, the 0.98:1 Si:Ti sample contained particles consisting of two distinct phases. Ehrmann et al. (1999) reported the formation of mixed oxides and segregated nanoparticles of similar morphology for 8:1 and 1:1 Si:Ti samples, respectively, and this supports our observations. Hung and Katz (1992) also studied the formation of $\mathrm{SiO}_{2} / \mathrm{TiO}_{2}$ binary oxide particles and reported that $\mathrm{TiO}_{2}$ nanoparticles can be coated with a silica layer whose thickness depends on the ratio of silica to titania precursor (at 3:1 Si to Ti ratio a 15-40 nm thick non-uniform silica coating and at $1: 1 \mathrm{Si}$ to Ti ratio a $14 \mathrm{~nm}$ thick, uniform silica coating was obtained). However, such particle morphologies are not observed at 3.2:1 $\mathrm{Si}$ to $\mathrm{Ti}$ and $0.98: 1 \mathrm{Si}$ to $\mathrm{Ti}$ ratios investigated in the present study. Instead, difference between the Ti-rich and Si-rich areas became more apparent with increasing concentrations of $\mathrm{TiO}_{2}$ as observed by Ehrmann et al. (1999). The ionic radius of $\mathrm{Ti}^{4+}$ is $0.61 \AA$, while that of $\mathrm{Si}^{4+}$ is $0.40 \AA$, small enough to enter the titania lattice interstitially which supports the observed mixed oxide formation with $\mathrm{SiO}_{2}$ and $\mathrm{TiO}_{2}$ (Vemury \& Pratsinis, 1995). The substitution of $\mathrm{Si}$ in the titania lattice also inhibits the transformation of anatase to rutile which is also observed and discussed in the following section.

Figure 7 shows the X-ray diffraction patterns for the samples with various $\mathrm{TiO}_{2} / \mathrm{SiO}_{2}$ concentrations. Reflections from the segregated anatase phase are observed for 3.2:1 and 0.98:1 Si:Ti samples. The intensity of the anatase peaks increase and peak widths narrow with the increasing concentration of $\mathrm{Ti}$, suggesting the formation of coarse segregated regions. These conclusions correlate well with the TEM pictures (Figure 6). At all the concentrations of the $\mathrm{TiO}_{2}$ investigated in the present study (23.3:1 Si:Ti to 0.98:1 Si:Ti), no rutile form of $\mathrm{TiO}_{2}$ is observed supporting the effect of Si substitution in stabilizing the anatase phase (Vemury \& Pratsinis, 1995). An increase in the size of the segregated anatase regions is expected with increasing Ti-precursor concentration since the initial particle number concentration increases and this augments the coagulation and coalescence rates, which results in larger primary particle sizes (Wegner \& Pratsinis, 2003b).

Figure 8 shows the TEM images of the 9.8:1 Si:Ti samples produced at various flow rates of oxygen. Segregation of $\mathrm{TiO}_{2}$ anatase is evident in the sample which was produced at a low oxygen flow rate of $250 \mathrm{l} / \mathrm{h}$ (Figure $8 \mathrm{a}$ ). Increasing the oxygen flow rate reduces the flame length and thus the particle residence time at high temperature is decreased. This, in turn, increases the quenching rate of particles and, consequently, phase segregation disappears and single phase mixed oxide particles are formed (Figure 8b, c). For the same precursor concentration, particles with different chemical homogeneity are formed depending on the process parameters. X-ray diffraction patterns of 3.2:1 Si:Ti samples produced at various oxygen flow rates are shown in Figure 9. With increasing oxygen flow rate, crystallite size of the anatase decreases as is evident from the observed increase in FWHM (full width at half maximum) of the anatase peaks. As discussed in the previous section, 

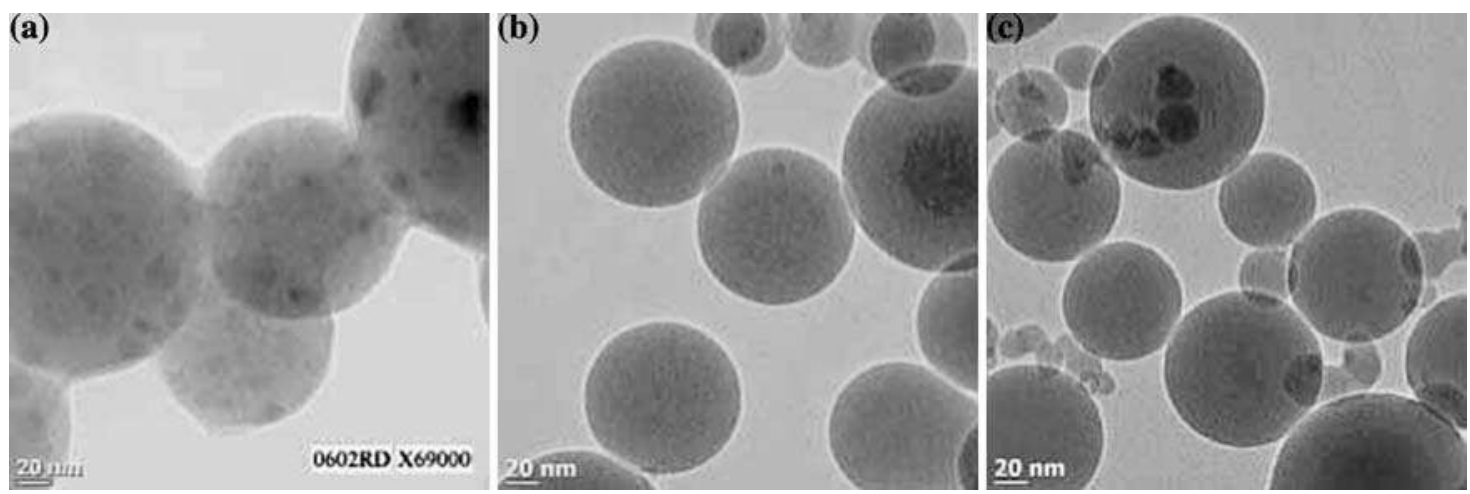

Figure 8. TEM images of mixed $\mathrm{TiO}_{2} / \mathrm{SiO}_{2}$ powders with 9.8:1 Si:Ti produced at various $\mathrm{O}_{2}$ flow rates: (a) 250 1/h, (b) 500 1/h and (c) $950 \mathrm{l} / \mathrm{h}$.

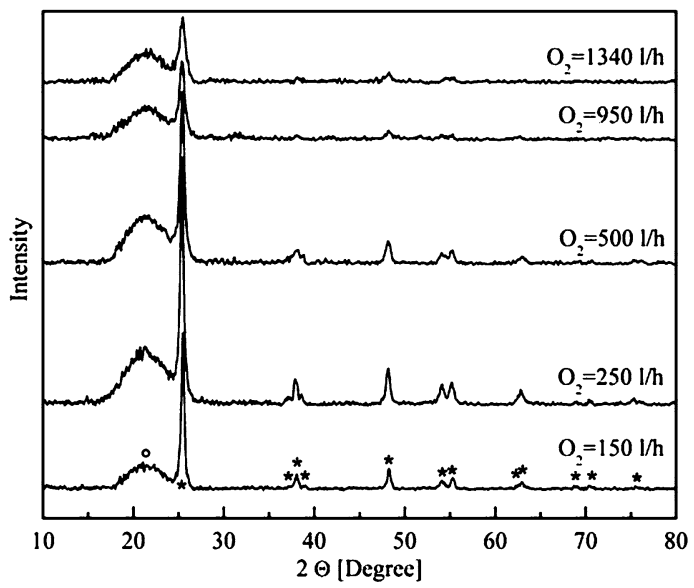

Figure 9. XRD patterns of mixed $\mathrm{TiO}_{2} / \mathrm{SiO}_{2}$ powders with 3.2:1 Si:Ti produced at various flow rates of $\mathrm{O}_{2} ;{ }^{\circ}$ indicates amorphous silica, * indicates peaks corresponding to anatase phase of $\mathrm{TiO}_{2}$.

increasing oxygen flow rate reduces the flame temperature (Zhu \& Kosugi, 1996) as additional $\mathrm{O}_{2}$ flow dissipates the generated heat very quickly and shortens the flame length (Mueller et al., 2004) due to the enhanced combustion rate. Moreover, quenching rate of the flame increases with the increase of oxygen flow rate leading to the reduced crystallite size of anatase. This shows the flexibility of diffusion flame reactors to vary the size of the segregated phase at a given concentration of the reactants. Variation of the size of segregated phase will influence the mechanical properties of the resultant material and can be used as optical wave guides (Backer et al., 1991). Ehrmann et al. (1999) observed a similar effect by collecting the particles at various distances from the tip of the flame.
To probe the interactions of $\mathrm{TiO}_{2}$ with $\mathrm{SiO}_{2}$, Raman spectroscopy was performed and the corresponding spectrum for $\mathrm{TiO}_{2} / \mathrm{SiO}_{2}$ is shown in Figure 10. Silica alone shows Raman features at $440,488,616,791,994-976$, and $1030-1040 \mathrm{~cm}^{-1}$. The last band is assigned to the asymmetric stretching of the $\mathrm{Si}-\mathrm{O}$ group and the band at $976 \mathrm{~cm}^{-1}$ is associated with the $\mathrm{Si}-\mathrm{OH}$ stretching mode of surface hydroxyls. The band at $791 \mathrm{~cm}^{-1}$ has been assigned to the symmetrical $\mathrm{Si}-\mathrm{O}-\mathrm{Si}$ stretching mode and the $440 \mathrm{~cm}^{-1}$ band to the $\mathrm{Si}-$ $\mathrm{O}-\mathrm{Si}$ bending mode, while the bands at 488 and $616 \mathrm{~cm}^{-1}$ have been assigned to the D1 and D2 symmetric stretching modes of vibrationally-isolated four-fold and three-fold rings of $\mathrm{SiO}_{2}$ tetrahedra (Brinker et al., 1988; Morrow \& Mcfarlan, 1990).

Considering first the 23.3:1 Si:Ti sample, additional bands appear at $950 \mathrm{~cm}^{-1}$ and $1080 \mathrm{~cm}^{-1}$ are associated with vibrational modes involving Ti-O-Si bonding (Gao et al., 1998). The intensities of these bands increase with increasing $\mathrm{TiO}_{2}$ content up to $9.8: 1 \mathrm{Si}$ Ti and decrease thereafter due to increased segregation of $\mathrm{TiO}_{2}$. At 9.8:1 $\mathrm{Si}: \mathrm{Ti}$, minute segregation of $\mathrm{TiO}_{2}$ is indicated by the presence of a weak anatase peak at $144 \mathrm{~cm}^{-1}$ and phase contrast in the TEM pictures. Thus, while X-ray diffraction measurements did not show any characteristic peaks from the segregated anatase, the high sensitivity of the Raman technique (minimum detectable amount of $0.05 \mathrm{wt} \%$; Bordiga et al., 1994) proves that segregation is occurring at this precursor concentration from a mixed oxide. Segregation of $\mathrm{TiO}_{2}$ as a distinctly separate phase is not seen in the 9.8:1 Si:Ti samples 


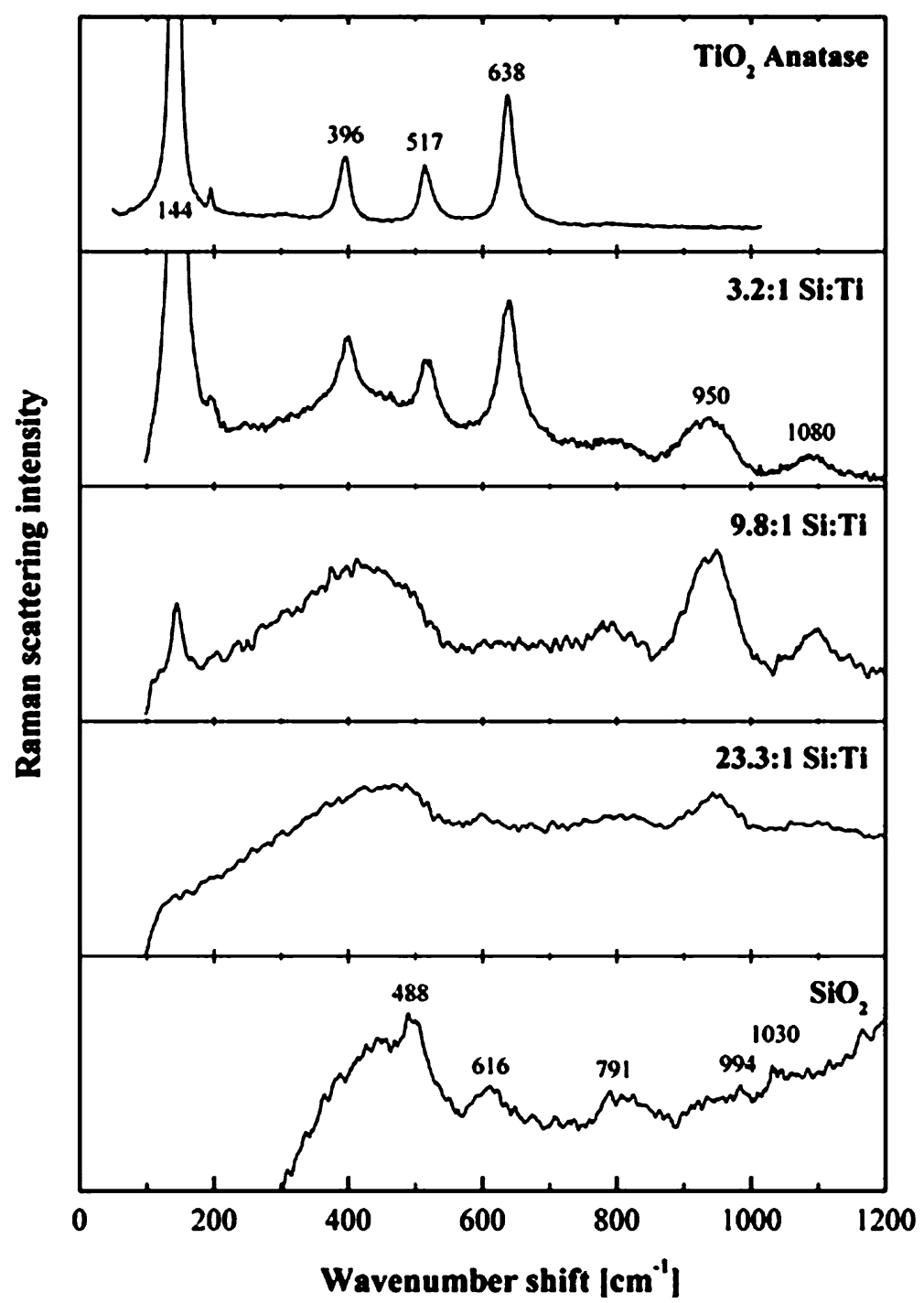

Figure 10. Raman spectra of $\mathrm{SiO}_{2}, \mathrm{TiO}_{2}$ and mixed $\mathrm{TiO}_{2} / \mathrm{SiO}_{2}$ powders synthesized at various mole concentrations of HMDSO/TTIP precursors and at $44 \mathrm{l} / \mathrm{h} \mathrm{CH}_{4}, 86 \mathrm{l} / \mathrm{h} \mathrm{N} \mathrm{N}_{2}$ and $250 \mathrm{l} / \mathrm{h} \mathrm{O}_{2}$. Corresponding peak wavenumber shifts for the pure oxides are indicated. The wavenumber shifts for the mixed oxide $\mathrm{Si}-\mathrm{O}-\mathrm{Ti}$ bonds are located at 950 and $1080 \mathrm{~cm}^{-1}$.

produced at higher flow rates of oxygen and it appears that the system tends to form as a mixed oxide due to enhanced quenching by the supplied oxygen.

Figure 3 shows the specific surface area of the composite $\mathrm{SnO}_{2} / \mathrm{SiO}_{2}$ aerosols at various concentrations of $\mathrm{SnO}_{2}$ as a function of oxygen flow rate. In contrast to the mixed $\mathrm{TiO}_{2} / \mathrm{SiO}_{2}$ aerosols, the surface area of the composite $\mathrm{SnO}_{2} / \mathrm{SiO}_{2}$ powders do not show much variation compared to the pure $\mathrm{SiO}_{2}$. Tin dioxide forms discrete particles on the surface of $\mathrm{SiO}_{2}$, as shown in the TEM images of the composite $\mathrm{SnO}_{2} / \mathrm{SiO}_{2}$ aerosol in (Figure 11). The most notable difference between the two systems (i.e., $\mathrm{TiO}_{2} / \mathrm{SiO}_{2}$ and $\mathrm{SnO}_{2} / \mathrm{SiO}_{2}$ ) is that phase segregation is obvious for every combination of $\mathrm{SiO}_{2}$ and $\mathrm{SnO}_{2}$. Reason for this segregation behavior is mainly due to very low solubility of $\mathrm{SnO}_{2}$ in $\mathrm{SiO}_{2}$ (Canevali et al., 2001) and is discussed in the later section.

In Figure 5, the differences in growth mechanism between $\mathrm{SiO}_{2}$ and $\mathrm{SnO}_{2}$ are summarized in 


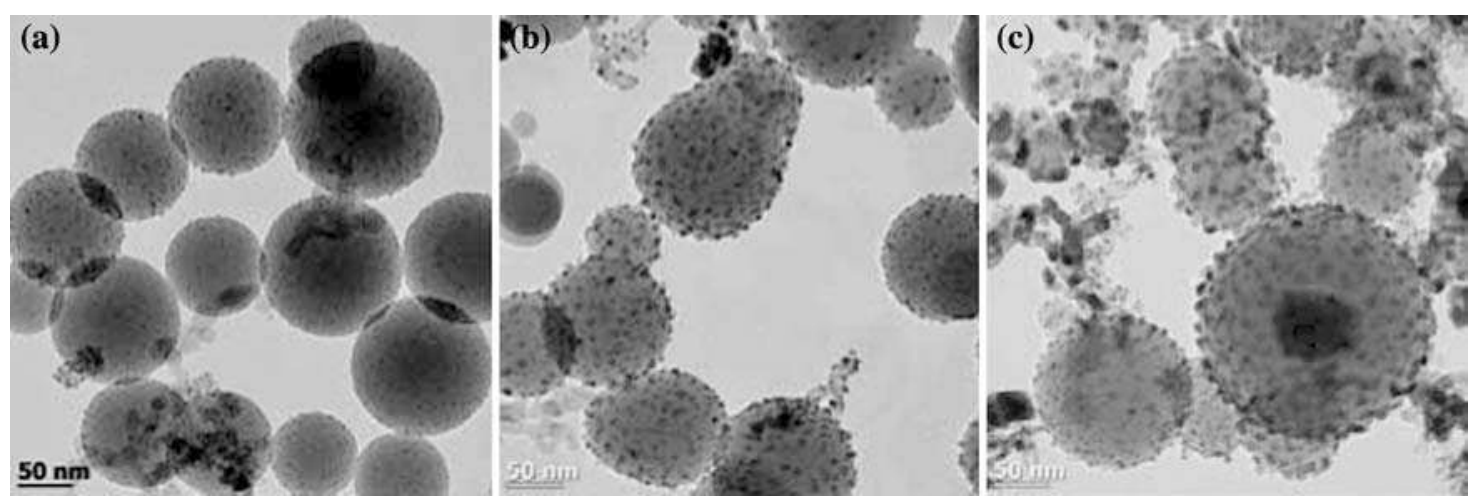

Figure 11. TEM images of composite $\mathrm{SnO}_{2} / \mathrm{SiO}_{2}$ powders produced at various concentrations of $\mathrm{HMDSO} / \mathrm{TMT}$ precursors and at 44 1/h CH4, 86 1/h N 2 and 250 1/h O $\mathrm{h}_{2}$ : (a) Si:Sn ratio 17.2:1, (b) Si:Sn ratio 6.1:1 and (c) Si:Sn ratio 1.8:1.

the form of a schematic of particle morphology as a function of residence time and temperature. Unlike $\mathrm{SnO}_{2}, \mathrm{SiO}_{2}$ particles nucleate in the flame where the temperature is close to its melting point (step II) (Hung \& Katz, 1992). Particles continue to grow by surface growth/aggregation (step III) and subsequently coalesce to form large primary particles. Hung and Katz (1992) used counter flow diffusion flames where the oxidant and the fuel have to diffuse and mix for combustion, similar to the co-flow diffusion flames used in the present study. So it is reasonable to predict that particle formation mechanism of $\mathrm{SiO}_{2}$ follows the same path in the co-flow diffusion flame used in the present study.

The processes occurring during multicomponent aerosol formation from the gas-phase precursors are the same as for the single component aerosol formation: chemical reaction, nucleation and aerosol growth. It is possible that differences in the chemical reaction kinetics of the precursors affect the arrangement of species for multicomponent aerosols. Ehrmann et al. (1998) reported that particles of uniform composition are formed if the interval between the half life (or characteristic times) of the reactions is negligible compared to the time required for particle formation and on the other hand chemical segregation is expected if the interval between the reactions is on the order of, or greater than the particle formation time. The particle formation mechanism of $\mathrm{SnO}_{2} / \mathrm{SiO}_{2}$ system is shown in Figure 5c. Initially, TMT precursor is oxidized to form $\mathrm{SnO}$ vapor at temperatures which are too low for the
$\mathrm{SiO}_{2}$ particles to nucleate. When $\mathrm{SiO}_{2}$ particles start to nucleate in step II, they form within the precursor vapor concentration of $\mathrm{SnO}$ which subsequently oxidizes and condenses onto the existing $\mathrm{SiO}_{2}$ particles (step III) whose particle number concentration is expected to be high due to the sluggish sintering behavior of $\mathrm{SiO}_{2}$. Ehrmann et al. (1998) showed that the scavenging of second species by pre-existing particles of the first species is favored for high aerosol volume loadings and large number concentration of small preexisting particles. In the final step, aggregated/ coagulated $\mathrm{SiO}_{2}$ particles sinter to form large primary particles while $\mathrm{SnO}_{2}$ particles still remains on the surface due to the very low solid solubility of $\mathrm{SnO}_{2}$ in $\mathrm{SiO}_{2}$. Chiodini et al. (1999) showed that the solid solubility of $\mathrm{SnO}_{2}$ in $\mathrm{SiO}_{2}$ is only $1 \mathrm{wt} \%$, while in the present work experiments were conducted with a minimum of $13 \mathrm{wt} \% \mathrm{SnO}_{2}$ ( $\mathrm{Si}: \mathrm{Sn}$ is 17.2:1).

The size of the condensed $\mathrm{SnO}_{2}$ particles is very small. This is because the number concentration of particles formed from $\mathrm{SnO}$ precursor vapor, which subsequently oxidizes to $\mathrm{SnO}_{2}$ particles, is reduced by dilution with the $\mathrm{SiO}_{2}$ aerosol and due to the fact that size of the $\mathrm{SnO}_{2}$ particles is primarily dependent on the precursor concentration and residence time rather than the flame temperature (Zhu \& Pratsinis, 1997). In general, the morphology of the crystalline $\mathrm{SnO}_{2}$ particles is faceted, as shown previously (Figure 4c). Zhu and Pratsinis (1997) also reported the same morphology for the tin dioxide particles in their research. In contrast 
very fine $\mathrm{SnO}_{2}$ particles of spherical shape condensed on silica particles. Such morphology of $\mathrm{SnO}_{2}$ particles (fine and non-aggregated) can have improved sensor performance (Feng et al., 2003). Probable reasons for the condensation of $\mathrm{SnO}_{2}$ on $\mathrm{SiO}_{2}$ particles are due to the greater difference in the surface energies between the two oxides $\left(\mathrm{SiO}_{2}: 0.3 \mathrm{~J} \mathrm{~m}^{-2}, \mathrm{SnO}_{2}: \sim 2 \mathrm{~J} \mathrm{~m}^{-2}\right.$ ) (Slater et al., 1999) and limited solubility of $\mathrm{SnO}_{2}$ in $\mathrm{SiO}_{2}$ (Chiodini et al., 1999).

The grain size of the condensed $\mathrm{SnO}_{2}$ increases from 4 to $15 \mathrm{~nm}$ (Figure $11 \mathrm{a}-\mathrm{c}$ ) as the precursor concentration $\mathrm{Si}: \mathrm{Sn}$ is increased from 17.2:1 to 1.8:1, respectively. This supports the statement made earlier that the growth of $\mathrm{SnO}_{2}$ particles primarily depends on the precursor concentration and residence time rather than flame temperature and proceeds via direct vapor phase condensation and oxidation of $\mathrm{SnO}$.

Figure 12 shows $\mathrm{X}$-ray diffraction patterns of the composite $\mathrm{SnO}_{2} / \mathrm{SiO}_{2}$ aerosols at various concentrations. Reflections corresponding to cassiterite confirm the phase segregation of $\mathrm{SnO}_{2}$ at all concentrations investigated in the present work. The intensity of the $\mathrm{SnO}_{2}$ reflections increases and width decreases with increasing $\mathrm{Sn}$ concentration in the precursor, suggesting an increase in the size of the resultant stannic oxide $\left(\mathrm{SnO}_{2}\right)$ particles.

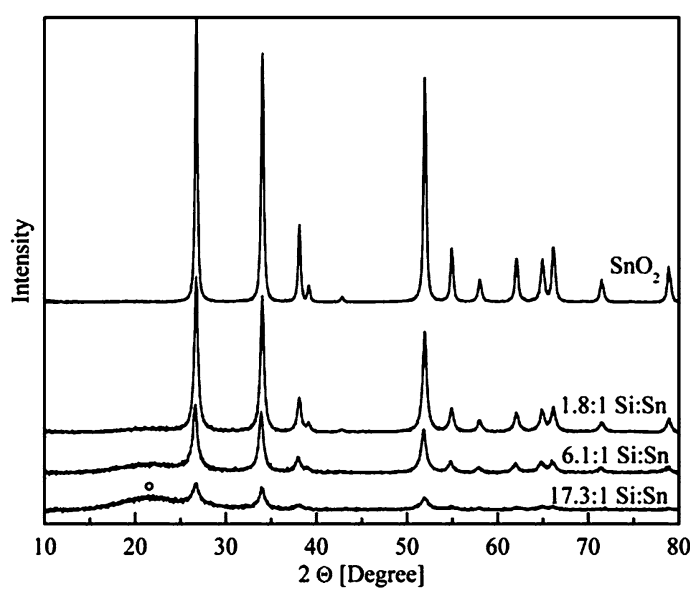

Figure 12. XRD patterns of composite $\mathrm{SnO}_{2} / \mathrm{SiO}_{2}$ powder produced at various concentrations of $\mathrm{HMDSO} / \mathrm{TMT}$ and at $44 \mathrm{l} / \mathrm{h} \mathrm{CH}_{4}, 86 \mathrm{l} / \mathrm{h} \mathrm{N}_{2}$ and $250 \mathrm{l} / \mathrm{h} \mathrm{O}_{2}$; ${ }^{\circ}$ indicates amorphous silica and all other peaks correspond to cassiterite phase of $\mathrm{SnO}_{2}$.

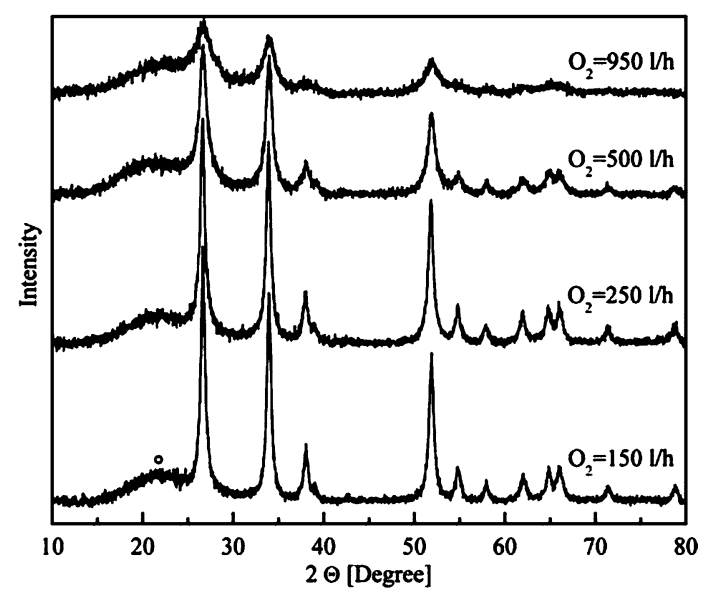

Figure 13. XRD patterns of composite $\mathrm{SnO}_{2} / \mathrm{SiO}_{2}$ powder with 6.1:1 Si:Sn produced at various flow rates of $\mathrm{O}_{2}$; ${ }^{\circ}$ indicates amorphous silica and all other peaks correspond to cassiterite phase of $\mathrm{SnO}_{2}$.

This conclusion is in agreement with the TEM observations.

It can be expected that the size of the condensed $\mathrm{SnO}_{2}$ particles should decrease with increasing oxygen flow rate. Increasing the oxygen flow rates induces two effects: (1) reduction of the flame height, which makes the residence time of the particles shorter and (2) dilution of the precursor concentration so that the rate of particles growth by coagulation/coalescence is reduced. These two factors hamper the particle growth and result in smaller particle sizes. These conclusions are supported by X-ray diffraction patterns of 6.1:1 Si:Sn samples produced at various oxygen flow rates shown in Figure 13 where the width of the $\mathrm{SnO}_{2}$ reflections increase, and hence the particle sizes decrease, with increasing oxygen flow rates. The size and size distribution of particles, large accessible surface associated with good crystallinity are very important requirements for $\mathrm{SnO}_{2}$ based gas sensors (Sahm et al., 2004). Weak thermal stability of the nanosized $\mathrm{SnO}_{2}$ particles could be overcome by the combination of $\mathrm{SnO}_{2} / \mathrm{SiO}_{2}$. This makes the particles produced in the present study as a good choice for the above mentioned application.

No mixed oxide formation is observed with $\mathrm{SnO}_{2} / \mathrm{SiO}_{2}$ particles as only the reflections corresponding to the pure $\mathrm{SiO}_{2}$ and $\mathrm{SnO}_{2}$ are observed with Raman spectroscopy. Results of XRF analysis on the powder samples confirmed the mole 
ratios of $\mathrm{Si}$ to $\mathrm{Ti}$ and $\mathrm{Sn}$ were approximately equal to that in the feed.

\section{Conclusions}

Formation of binary $\mathrm{TiO}_{2} / \mathrm{SiO}_{2}$ and $\mathrm{SnO}_{2} / \mathrm{SiO}_{2}$ nanoparticles in atmospheric pressure diffusion flames has been investigated. It has been shown by XRD, TEM and Raman spectroscopy that the arrangement of chemical species in the multicomponent aerosols follows the phase segregation expected from the equilibrium phase diagrams of the respective system. The phase composition in equilibrium at elevated temperatures is retained at room temperature in all cases. Furthermore, the data show that the distribution of the chemical species can be shifted considerably away from equilibrium by changing the process parameters to give various modes of interactions between two species at the same concentration. Differences between the segregation behavior of $\mathrm{TiO}_{2} / \mathrm{SiO}_{2}$ and $\mathrm{SnO}_{2} / \mathrm{SiO}_{2}$ have been explained by considering the differences in the equilibrium phase distribution of the systems at high temperatures and liquid phase solubility of $\mathrm{TiO}_{2}$ and $\mathrm{SnO}_{2}$ in $\mathrm{SiO}_{2}$. It has also been demonstrated that the size of the segregated second phase regions can be controlled by changing the oxygen flow rate.

\section{Acknowledgements}

The authors would like to acknowledge the EC and the Swiss BBW for their support of the FP5-Project Photocoat (EU contract No G5RD-CT-2002-00861; BBW project No 01.05711) and also Dr. Markus Wegmann and Dr. R.B. Diemer for their contributions to this work.

\section{References}

Aizawa M., Y. Nosaka \& N. Fujii, 1991. FT-IR liquid attenuated total reflection study of $\mathrm{TiO}_{2}-\mathrm{SiO}_{2}$ sol-gel reaction. J. Non Cryst. Solids 128, 77-85.

Anderson C. \& A.J. Bard, 1995. An improved photocatalyst of $\mathrm{TiO}_{2} / \mathrm{SiO}_{2}$ prepared by a sol-gel synthesis. J. Phys. Chem. 99, 9882-9885.
Astier M. \& P. Vergnon, 1976. Determination of the diffusion coefficients from sintering data of ultrafine oxide particles. J. Solid State Chem. 19, 67-73.

Atik M. \& J. Zarzycki, 1994. Protective $\mathrm{TiO}_{2}-\mathrm{SiO}_{2}$ coatings on stainless-steel sheets prepared by dip-coating. J. Mater. Sci. Lett. 13, 1301-1304.

Backer M.R., R. Cavender, M.L. Elder, P.C. Jones \& J.A. Murphy, 1991. U.S. Patent number 5,067,975.

Bordiga S., S. Coluccia, C. Lamberti, L. Marchese, A. Zecchina, F. Boscherini, F. Buffa, F. Genoni, G. Leofanti, G. Petrini \& G. Vlaic, 1994. XAFS study of Ti-silicalite: structure of framework $\mathrm{Ti}(\mathrm{IV})$ in the presence and absence of reactive molecules $\left(\mathrm{H}_{2} \mathrm{O}, \mathrm{NH}_{3}\right)$ and comparison with ultraviolet-visible and IR results. J. Phys. Chem. 98, 4125-4132.

Brambilla G., V. Pruneri \& L. Reekie, 2000. Photorefractive index gratings in $\mathrm{SnO}_{2}: \mathrm{SiO}_{2}$ optical fibers. Appl. Phys. Lett. 76, 807-809.

Brinker C.J., R.J. Kirkpatrick, D.R. Tallant, B.C. Bunker \& B. Montez, 1988. NMR confirmation of strained "defects" in amorphous silica. J. Non Cryst. Solids 99, 418-428.

Canevali C., N. Chiodini, F. Morazzoni, J. Padovani, A. Paleari, R. Scotti \& G. Spinolo, 2001. Substitutional tindoped silica glasses: an infrared study of the sol-gel transition. J. Non-Cryst. solids 293(295), 32-38.

Cardoso W.S., M.S.P. Francisco, A.M.S. Lucho \& Y. Gushilem, 2004. Synthesis and acidic properties of the $\mathrm{SiO}_{2} / \mathrm{SnO}_{2}$ mixed oxides obtained by the sol-gel process. Evaluation of immobilized copper hexacyanoferrate as an electrochemical probe. Solid State Ionics 167, 165-173.

Carturan G., R. Ceccato, G. Principi \& U. Russo, 1995. Structural-analysis of mixed tin oxides produced by the solgel method. J. Radioanal. Nucl. Chem. 190, 419-423.

Chiodini N., A. Paleari, D. DiMartino \& G. Spinolo, 2002. $\mathrm{SnO}_{2}$ nanocrystals in $\mathrm{SiO}_{2}$ : a wide-band-gap quantum-dot system. Appl. Phys. Lett. 81, 1702-1704.

Chiodini N., A. Paleari, G. Spinolo \& P. Crespi, 2001. Photorefractivity in $\mathrm{SiO}_{2}: \mathrm{SnO}_{2}$ glass-ceramics by visible light. J. Non-Cryst. Solids 322, 266-271

Chiodini N., F. Morazzoni, A. Paleari, R. Scotti \& G. Spinolo, 1999. Sol-gel synthesis of monolithic tin-doped silica glass. J. Mater. Chem. 9, 2653-2658.

Cox D.F., T.B. Fryberger \& S. Semancik, 1998. Oxygen vacancies and defect electronic states on the $\mathrm{SnO}_{2}(110)$ $1 \times 1$ surface. Phys. Rev. B 38, 2072-2083.

Dagan G., S. Sampath \& O. Lev, 1995. Preparation and utilization of organically modified silica-titania photocatalysts for decontamination of aquatic environments. Chem. Mater. 7, 446-453.

DeVries R.C., R. Roy \& E.F. Osborn, 1954. The system $\mathrm{TiO}_{2}-$ $\mathrm{SiO}_{2}$. Trans. Br. Ceram. Soc. 53, 525-540.

Ehrmann S.H., S.K. Friedlander \& M.R. Zachariah, 1998. Characteristics of $\mathrm{SiO}_{2} / \mathrm{TiO}_{2}$ nanocomposite particles formed in a premixed flat flame. J. Aerosol Sci. 29, 687-706.

Ehrmann S.H., S.K. Friedlander \& M.R. Zachariah, 1999. Phase segregation in binary $\mathrm{SiO}_{2} / \mathrm{TiO}_{2}$ and $\mathrm{SiO}_{2} / \mathrm{Fe}_{2} \mathrm{O}_{3}$ nanoparticle aerosols formed in a premixed flame. J. Mater. Res. 14, 4551-4561. 
Feng Y.S., S.M. Zhou, Y. Li \& L.D. Zhang, 2003. Preparation of the $\mathrm{SnO}_{2} / \mathrm{SiO}_{2}$ xerogel with a large specific surface area. Mater. Lett. 57, 2409-2412.

Gao X., S.R. Bare, J.L.G. Fierro, M.A. Banares \& I.E. Wachs, 1998. Preparation and in-situ spectroscopic characterization of molecularly dispersed titanium oxide on silica. J. Phys. Chem. B 102, 5653-5666.

Harrison P.G. \& M.J. Willett, 1989. Tin oxide surfaces. J. Chem. Soc. Farady Trans. 85, 1921-1932.

Hung C.H. \& J.L. Katz, 1992. Formation of mixed oxide powders in flames: Part I. $\mathrm{TiO}_{2}-\mathrm{SiO}_{2}$. J. Mater. Res. 7, 1861-1869.

Ishida T., H. Kobayashi \& Y. Nakato, 1993. Structures and properties of electron-beam-evaporated indium tin oxide films as studied by X-ray photoelectron spectroscopy and work-function measurements. J. Appl. Phys. 73, 4344-4350.

Jang H.D. \& S.K. Kim, 2001. Controlled synthesis of titanium dioxide nanoparticles in a modified diffusion flame reactor. Mater. Res. Bull. 36, 627-637.

Johannessen T., S.E. Pratsinis \& H. Livbjerg, 2001. Computational analysis of coagulation and coalescence in the flame synthesis of titania particles. Powder Technol. 118, 242-250.

Kennedy M.K., F.E. Kruis \& H. Fissan, 2000. Gas phase synthesis of size selected $\mathrm{SnO}_{2}$ nanoparticles for gas sensor applications. J. Metastable Nanocryst. Mat. 8, 949-954.

Kingery W.D., H.K. Bowen \& D.R. Uhlmann,. 1976. Introduction to Ceramics. New York: Wiley-Interscience 494.

Kodas T.T., E.M. Engler \& V.Y. Lee, 1989. Generation of thick $\mathrm{Ba}_{2} \mathrm{YCu}_{3} \mathrm{O}_{7}$ films by aerosol deposition. Appl. Phys. Lett. 54, 1923-1925.

Lee S.K., K.W. Chung \& S.G. Kim, 2002. Preparation of various composite $\mathrm{TiO}_{2} / \mathrm{SiO}_{2}$ ultrafine particles by vaporphase hydrolysis. Aerosol. Sci. Tech. 36, 763-770.

Lindackers D., C. Janzen, B. Rellinghaus, E.F. Wassermann \& P. Roth, 1998. Synthesis of $\mathrm{Al}_{2} \mathrm{O}_{3}$ and $\mathrm{SnO}_{2}$ particles by oxidation of metalorganic precursors in premixed $\mathrm{H}_{2} / \mathrm{O}_{2} / \mathrm{Ar}$ low pressure flames. Nanostruct. Mater. 10, 1247-1270.

Miller J.B., S.T. Johnston \& E.I. Ko, 1994. Effect of prehydrolysis on the textural and catalytic properties of titania-silica aerogels. J. Catal. 150, 311-320.

Miyamoto Y., S. Kirihara \& S. Kanehira, 2004. Smart processing development of photonic crystals and fractals. Int. J. Appl. Ceram. Technol. 1, 40-48.

Morrow B.A. \& A.J. Mcfarlan, 1990. Chemical reactions at silica surfaces. J. Non-Cryst. Solids 120, 61-71.

Mueller R., H.K. Kammler, S.E. Pratsinis, A. Vital, G. Beaucage \& P. Burtscher, 2004. Non-agglomerated dry silica nanoparticles. Powder Technol. 140, 40-48.

Niles D.W., D. Rioux \& H. Hochst, 1993. A photoemission investigation of the $\mathrm{SnO}_{2} / \mathrm{CdS}$ interface: a front contact interface study of $\mathrm{CdS} / \mathrm{CdTe}$ solar cells. J. Appl. Phys. 73, 4586-4590.

Popova L., R. Djulgerova, G. Beshkov, V. Mihailov, A. Szytula, L. Gondek \& Z.J. Petrovic, 2004. $\mathrm{SnO}_{2}$ thin films for gas sensors modified by hexamethyldisilazane after rapid thermal annealing. Sensor. Actuat. B-Chem. 100, 357-363.

Powell Q.H., G.P. Fotou, T.T. Kodas, B.M. Anderson \& Y.X. Guo, 1997. Gas-phase coating of $\mathrm{TiO}_{2}$ with $\mathrm{SiO}_{2}$ in a continuous flow hot-wall aerosol reactor. J. Mater. Res. 12, 552-559.

Pratsinis S.E. \& S. Vemury, 1996. Particle formation in gases: a review. Powder Technol. 88, 267-273.

Sahm T., L. Maedler, A. Gurlo, N. Barsan, S.E. Pratsinis \& U. Weimar, 2004. Flame spray synthesis of tin dioxide nanoparticles for gas sensing. Sensor. Actuat. B-Chem. 98, 148-153.

Salas P., J.G. Hernandez, J.A. Montoya, J. Navaretter, J. Salmones, I. Schifter \& J. Morales, 1997. Effect of tin content on silica mixed oxides: sulfated and unsulfated catalysts. J. Mol. Catal. A: Chem. 123, 149-154.

Song Y., T. Sakurai, K. Kishimoto, K. Maruta, S. Matsumoto \& K. Kikuchi, 1998. Synthesis and optical properties of lowtemperature $\mathrm{SiO}_{\mathrm{x}}$ and $\mathrm{TiO}_{\mathrm{x}}$ thin films prepared by plasma enhanced CVD. Vacuum 51, 525-530.

Schultz P.C., 1976. Binary titania-silica glasses containing 10 $20 \mathrm{wt} \% \mathrm{TiO}_{2}$. J. Am. Ceram. Soc. 59, 214-219.

Slater B., C.R.A. Catlow, D.H. Gay, D.E. Williams \& V. Dusastre, 1999. Study of surface segregation of antimony on $\mathrm{SnO}_{2}$ surfaces by computer simulation techniques. J. Phys. Chem. B 103, 10,644-10,650.

Srinivasan S., A.K. Datye, M.H. Smith \& C.H.F. Peden, 1994. Interaction of titanium isopropoxide with surface hydroxyls on Silica. J. Catal. 145, 565-573.

Stakheev A.Y., E.S. Shpiro \& J. Apijok, 1993. XPS and XAES study of titania-silica mixed oxide system. J. Phys. Chem. 97, 5668-5672.

Stark W.J., S.E. Pratsinis \& A. Baiker, 2001. Flame made titania/silica epoxidation catalysts. J. Catal. 203, 516-524.

Vemury S., S.E. Pratsinis \& L. Kibbey, 1997. Electrically controlled flame synthesis of nanophase $\mathrm{TiO}_{2}, \mathrm{SiO}_{2}$ and $\mathrm{SnO}_{2}$ powders. J. Mater. Res. 12, 1031-1042.

Vemury S. \& S.E. Pratsinis, 1995. Dopants in flame synthesis of titania. J. Am. Ceram. Soc. 78, 2984-2992.

Wegner K. \& S.E. Pratsinis, 2003a. Scale-up of nanoparticle synthesis in diffusion flame reactors. Chem. Eng. Sci. 58, 4581-4589.

Wegner K. \& S.E. Pratsinis, 2003b. Nozzle-quenching process for controlled flame synthesis of titania nanoparticles. AICHE J. 49, 1667-1675.

Yu-Zhang K., G. Boisjolly, J. Rivory, L. Kilian \& C. Colliex, 1994. Characterization of $\mathrm{TiO}_{2} / \mathrm{SiO}_{2}$ multilayers by high resolution transmission electron microscopy and electron energy loss spectroscopy. Thin Solid Films 253, 299-302.

Zhu D. \& T. Kosugi, 1996. Thermal conductivity of $\mathrm{GeO}_{2}$ $\mathrm{SiO}_{2}$ and $\mathrm{TiO}_{2}-\mathrm{SiO}_{2}$ mixed glasses. J. Non-Cryst. Solids 202, 88-92.

Zhu W. \& S.E. Pratsinis, 1997. Synthesis of $\mathrm{SiO}_{2}$ and $\mathrm{SnO}_{2}$ particles in diffusion flame reactors. AIChE J. 43, 2657-2664. 